To cite this article: Flores-Baquero, O., Gallego-Ayala, J., Giné-Garriga, R., Jiménez-Fdez. de Palencia, A., Pérez-Foguet, A., 2016. The Influence of the Human Rights to Water and Sanitation Normative Content in Measuring the Level of Service. Soc. Indic. Res. 1-24.

To link to this article: $h$ ttp://dx.doi.org/10.1007/s11205-016-1374-6

The influence of the Human Rights to Water and Sanitation normative content in measuring the level of service

O Flores-Baquero*,** 1, J. Gallego-Ayala*** 2, R. Giné-Garriga*** 3, A. Jiménez-Fdez. de Palencia*,***4, A. Pérez-Foguet*,** 5

* Engineering Sciences and Global Development (ESc\&GD), Universitat Politècnica de Catalunya, Barcelona (UPC), Spain

** University Research Institute for Sustainability Science and Technology (IS.UPC), Universtiat Politècnica de Catalunya (UPC), Spain

***Water Regulatory Council of Mozambique, Mozambique

**** Stockholm International Water Institute (SIWI), Sweden

Email1': oscar.flores.baquero@upc.edu 


\title{
The Influence of the Human Rights to Water and Sanitation Normative Content in Measuring the Level of Service
}

\begin{abstract}
Human Rights to Water and Sanitation (HRWS) have been consolidated as relevant frameworks to measure different levels of services. It is essential to move forward with specific initiatives that interpret the content of these human rights and operationalize them through specific metrics. However, some critical issues emerge in attempting this. Different approaches are proposed in this article to tackle this challenge: $i$ ) utilizing a participatory technique to discuss the relative importance of the normative criteria to define water and sanitation services, $i$ ) defining a short list of key indicators to measure the different dimensions of HRWS, and iii) assessing the impact of different weighting systems in the constructing an aggregated index, which has been proposed as a useful tool to monitor water, sanitation, and hygiene (WASH) from a rights perspective. Two municipalities (in Mozambique and Nicaragua) were selected as initial case studies. The results suggest that there is a common understanding among the experts about prioritization of the HRWS criteria. Differences in the relative importance given to the HRWS criteria can be explained due to the particularities of the local context. Further, the research suggests that expert opinions may be partially conditioned by targets and indicators proposed at the international level. Although the influence of weighting techniques on aggregated measures and their utilization in the decision-making process are limited, this methodology has a great potential for adapting specific WASH metrics to different regional, national, and/or local contexts taking into account the HRWS normative content.
\end{abstract}

Keywords: Composite indicator; Human rights; WASH; Nicaragua; Mozambique; Sustainable Development Goals; AHP 


\section{Introduction}

Human Rights to Water and Sanitation (HRWS) gained international recognition on 2010 with the resolutions taken by the General Assembly of the United Nations (UN) and the UN Human Rights Council (United Nations 2010a; United Nations 2010b). Since then, water and sanitation experts have worked to clarify the scope and core content of the right to water and how to put the theoretical concepts into practice at the grass root level. Specifically, it is now essential to move forward and to define initiatives that allow the holistic approach of the HRWS (dimensions, elements, and indicators) to be interpreted and operationalized.

HRWS have been interpreted as rights to the access of these essential services (Irujo 2007). The first Special Rapporteur on the human rights to safe drinking water and sanitation proposes five distinct normative criteria, namely availability, quality/safety, physical accessibility, affordability (or economic accessibility), and acceptability (United Nations 2010c). Despite existing differences in the interpretation of the content of these two human rights (United Nations General Assembly 2015), experts propose to use the same five dimensions (COHRE WaterAid COSUDE and UN-HABITAT 2008; Langford et al. 2014, United Nations 2009a). In this regard, the theoretical approaches proposed by COHRE (Roaf et al. 2005), The Danish Institute of Human Rights (2014), and the United Nations (UN Special Rapporteur on the human right to safe drinking water and sanitation, 2014), among others, to operationalize the monitoring of HRWS criteria should be highlighted. Other authors have elaborated on the normative content to measure levels of service using outcome indicators (Flores Baquero et al. 2015). In addition, the use of composite indicators or indices to analyse complex water and sanitation linkage is widespread in the water, sanitation, and hygiene (WASH) sector (Feitelson and Chenoweth 2002; Gallego-Ayala et al. 2014; Giné Garriga and Pérez Foguet 2013; Jemmali and Sullivan 2014; Komnenic et al. 2009; Molle and Mollinga 2003; Pérez-Foguet and Giné Garriga 2011; Sullivan, 2002, Sullivan et al., 2003). For instance, the Joint Monitoring Programme (JMP) post-2015 targets and indicators for drinking water, sanitation, and hygiene (Joint Monitoring Programme 2014a) partially take this human rights normative content as a starting point when defining levels of service (Flores et al., 2015). Different NGOs (ONGAWA - Engineering for Human Development 2015; WASHwatch.org 2014), research centres (Moriarty et al. 2013), and even private water operators (AquaFed 2014) are likewise evolving in this sense.

Taking into consideration the current state of the art of the approaches followed to analyse HRWS, three aspects emerge as critical issues when assessing levels of WASH services from a rights perspective: $i$ ) how to measure each dimension of both rights in the field (see Flores et al. 2013), ii) how to assess the relative importance of each dimension when combining them, while ensuring that the methodologies are flexible enough to be contextually relevant, which is especially critical in the case of human rights as the mandate holder highlights (United Nations 2012), and iii) how to use adequate procedures to construct a composite indicator (Cho et al. 2010; Flores et al. 2013; Giné Garriga and Pérez-Foguet 2010; Hajkowicz 2006; OECDJRC 2008). This manuscript aims to address these challenges. 
First, we aim to define and interpret the HRWS criteria from a practitioner point of view as well as to propose a short list of key indicators by which they can be assessed. The UN Special Rapporteur (2014) provides the basis for monitoring HRWS in a broad sense, but the handbook still leaves us with the problem of defining specific indicators. The seminal work by Roaf et al. (2005) contributes with concrete indicators on the basis of General Comment 15, which is mainly based on the right to water. Other authors (Flores Baquero et al. 2015, Flores et al. 2013, The Danish Institute for Human Rights 2014) have made progress on this issue, as they propose specific metrics for monitoring levels of water service from a rights perspective. Nonetheless, despite this body of literature, the identification of adequate indicators remains elusive.

Second, this research aims to analyse expert opinions on the relative importance of the HRWS criteria. Bearing in mind that context-based approaches are necessary from a human rights perspective, the Analytic Hierarchy Process (AHP) is used as a consultative technique. AHP has been widely used in the scientific literature to take into consideration the local context in the fields of public opinion (Duke and Aull-Hydeb 2002; Gómez-Limón and Atance 2004; Kim et al. 2015) and strategic planning (Bryan et al. 2010; Grošelj et al. 2015; Lee and Chan 2008), and to permit the construction of composite indicators (Gallego-Ayala and Juizo 2012; Gómez-Limón and Sanchez-Fernandez 2010; Singh et al. 2007)

Third, this article aims to implement outputs from the first two objectives to construct a composite indicator. A key step in index construction is the definition of the relative importance of indicators within the composite, i.e. weight assignment. Indeed, accurately analyzing the relative importance of the indicators is a fundamental step when developing practical tools for sector performance monitoring, and this article proposes a method of integrating expert opinions in this process. Relevant research has suggested that the impact of weights in the final index values is reduced (Booysen 2002; Giné Garriga and Pérez-Foguet 2010; OECD-JRC 2008). However, the impact of different weighting systems on the final index-related outcomes (e.g., league tables, ranks, prioritization mechanism, etc.) may be substantial. While this crucial step of assigning weights to the different rights dimensions can be carried out using a wide array of techniques, none of them is above criticism. OECD-JRC (2008) classifies the available weighting techniques in three different groups: a) statistical tools, b) participatory tools, and c) equal weights. Multivariate and statistical techniques have been singled out, as they present an empirical and objective option for weight assignment. However, they have also been questioned, since they do not always reflect the priorities of decision-makers (Esty and Porter, 2005), and since the data-specific formulations have to be updated when more data are available (Lohani and Todino, 1984). Consultation with experts has the advantage of providing a flexible tool that is simple to use and easy to understand, but it is a relatively subjective method of weighting and is often singled out for its arbitrariness (Booysen, 2002). The main argument for equal indicator weights is based on the premise that no objective mechanism exists to assess the relative importance of the different aspects included in the index structure (Giné Garriga and Pérez-Foguet, 2010). This article contributes to this ongoing debate. A comparative analysis of these three weighting techniques has been carried out through two illustrative case studies from Mozambique and Nicaragua, with a focus on the differences produced in both the final index values and the related prioritization lists. 


\section{Methods}

This study has clear methodological foundations, which are briefly discussed in this section. First, the article deepens the understanding of the HRWS content through the operationalization of their definition into specific metrics; the composition of the criteria and indicators proposed for each criteria are presented. Second, the AHP method used to assess experts opinion on relative importance of human rights criteria is described. Third, the section provides a brief description of the main theoretical and practical considerations assumed for index construction. The two selected study areas for testing the applicability and validity of the proposed methodology are briefly described in the final subsection.

\subsection{From the concept of HRWS to specific metrics}

First, this study proposes a specific interpretation of the contents of HRWS. We base this interpretation on the General Comment No. 15 (United Nations 2002) and other reports of the first independent expert on the issue of human rights obligations related to access to safe drinking water and sanitation (UN Special Rapporteur on the Human Right to Safe Drinking Water and Sanitation 2014; United Nations 2009a; United Nations 2010c).Tables 1 and 2 present all five normative criteria for water and sanitation, respectively. Key concepts and a definition of criteria have been included. Based on this conceptual framework, an initial set of social indicators to measure these criteria has been proposed (see Table 3). The proposal presented herein is a step forward in the operationalization of these emerging human rights, particularly from a practitioner's perspective. 


\section{CRITERIA KEY CONCEPTS}

Availability Acceptable quantity for domestic uses; continuity

Physical

Accessibility

Distance from the dwelling to the water point; time spent on hauling water; source-to-person ratio; safe and convenient path for all easy-to-use and adapted technology

Quality /

safety

Safe drinking quality; guidelines for drinkingwater quality

Affordability Reasonable price (water connections and water services) for all; capacity of people to pay for water in addition to acquiring other basic goods

Acceptability our; odour; taste; cultural issues related to the service

\section{DEFINITION}

The water supply for each person must be sufficient and continuous for personal and domestic uses. These uses ordinarily include drinking, personal sanitation, clothes washing, food preparation, and personal and household hygiene. The quantity of water available for each person should correspond to World Health Organization (WHO) guidelines. Neither continuity nor exact quantity required can be determined in the abstract, since individual requirements for water consumption vary, for instance due to climatic conditions, level of physical activity, and personal health conditions.

Water facilities must be physically accessible for everyone within, or in the immediate vicinity of, each household, health or educationa institution, public institutions and places, and workplace. Even where water facilities exist, they are frequently inaccessible for different reasons. Around the world, water points are often a long distance from the home, so people, especially girls and women, spend major portions of their day walking to collect water for their daily needs. The distance to water source should be within reach of every household, bearing in mind the special needs of certain groups and individuals; a high source-to-person ratio often undermines physical accessibility; people's security is often threatened on their way to the service or while using it. The path leading to the facility or water source itself should be safe and convenient for all users, including children, older people, persons with disabilities, women (including pregnant women), and chronically ill people; the facility itself should be accessible for all users and easy to use.

Water must be of such a quality that it does not pose a threat to human health. The transmission of water-borne diseases via contaminated water must be avoided. In its Guidelines for Drinking-water Quality. WHO defines safe drinking water as water that "does not represent any significant risk to health over a lifetime of consumption, including different sensitivities that may occur between life stages". The maximum limits provided in the Guidelines for a wide range of potentially harmful substances can serve as a reference point.

Water facilities and services must be available for use at a price that is affordable to all people. The provision of services includes construction, maintenance of facilities and treatment of water. Paying for these services must not limit people's capacity to acquire other basic goods and services guaranteed by human rights, such as food, housing, health services and education. Affordability does not necessarily require services to be provided free of charge. Special caution must be exercised and due process guaranteed in cases of disconnection from the water supply due to a user's inability to pay. Measures must be in place to ensure that such users are not deprived of access to safe water to meet their most basic personal and domestic needs.

Perspectives differ with regard to which water supply solutions are acceptable in a given context. Acceptability is relevant for encouraging people to use safe water sources. In particular, water should be of an acceptable colour, odour, and taste. The placement of a water point or the actual water source should also be acceptable to them. Cultural prescriptions may also apply to conditions for use of these facilities. 


\section{CRITERIA KEY CONCEPTS}

Availability Sufficient number of facilities; individual and/or shared facilities according to the context

Physical accessibility

Reliable accessibility; accessible at all times of day and night; reasonable waiting times; safe and convenient path for all; easy-to-use and adapted technology

Quality /

safety

Technical safety; hygienic safety; access to safe water for hand washing and other hygiene practices; menstrual hygiene management; hygienic cleaning and emptying of pits; safe management and disposal of human urine and faeces

Affordability Reasonable price of sanitation services for al

Acceptability Cultural issues related to the service; privacy; gender issues

\section{DEFINITION}

There must be a sufficient number of sanitation facilities (with associated services) within, or in the immediate vicinity, of each household, health or educational institution, public institutions and places, and workplace. Although it is tempting to determine a specific minimum number of toilets needed to meet the requirement of availability, such determinations can be counterproductive in human rights terms. It must be recognised that not only a latrine at home but also shared or even public facilities could satisfied availability criteria in some contexts. It is crucial that the assessment of the sanitation requirements of any community is informed by the context, as well as the characteristics of particular groups, which may have different sanitation needs. In this regard, participation is a vital aspect of meeting human rights obligations with respect to sanitation.

Sanitation facilities must be physically accessible for everyone, i.e. accessibility must be reliable, include access at all times of day and night, and with waiting times are not unreasonably long. The location of sanitation facilities is critical, as it must ensure minimal risks to the physical security of users. This has particular implications for the path leading to the facility, which should be safe and convenient for all users, especially those with special access needs, such as children, persons with disabilities, elderly persons, pregnant women, parents accompanying children, and chronically ill people and those accompanying them. Moreover, sanitation facilities should be constructed to guarantee the physical integrity while using them, minimizing the risk of attack from animals and people, particularly for women and children.

To meet the standard of quality, the focus is on both the individual user and the affected collective. For individual users, sanitation facilities must be technically safe to use, which means that the superstructure is stable and the floor is designed to reduce the risk of accidents. Special attention should be paid to the safety needs of persons with disabilities, as well as the safety needs of children. Sanitation facilities must also be hygienically safe to use, which means that they effectively prevent human, animal, and insect contact with human excreta, and that excreta is safely disposed in situ or treated off-site. Sanitation facilities must further ensure access to water for hand washing and anal and genital cleansing. The facility has to be equipped for adequate menstrual hygiene management, which includes the hygienic disposal of menstrual products. For both individuals and the collective, regular cleaning, emptying of pits or other places that collect human excreta, and maintenance are essential to ensure the sustainability of sanitation facilities and continued access.

Access to sanitation facilities and services, including construction, emptying, and maintenance of facilities, as well as treatment and disposal of faecal matter, must be available at a price that is affordable for all people without limiting their capacity to acquire other basic goods and services, including water, food, housing, health, and education guaranteed by other human rights. Water disconnections resulting from an inability to pay also impact waterborne sanitation, and this must be taken into consideration before disconnecting the water supply.

Sanitation facilities and services must be culturally acceptable. Personal sanitation is still a highly sensitive issue across regions and cultures, and differing perspectives about which sanitation solutions are acceptable must be taken into account regarding design, positioning, and conditions for use of sanitation facilities. In many cultures, to be acceptable, construction of toilets need to ensure privacy. In most cultures, acceptability will require separate facilities for women and men in public places, and for girls and boys in schools. Facilities will need to allow for culturally acceptable hygiene practices. 
Table 3.Water and sanitation indicators based on human rights normative content

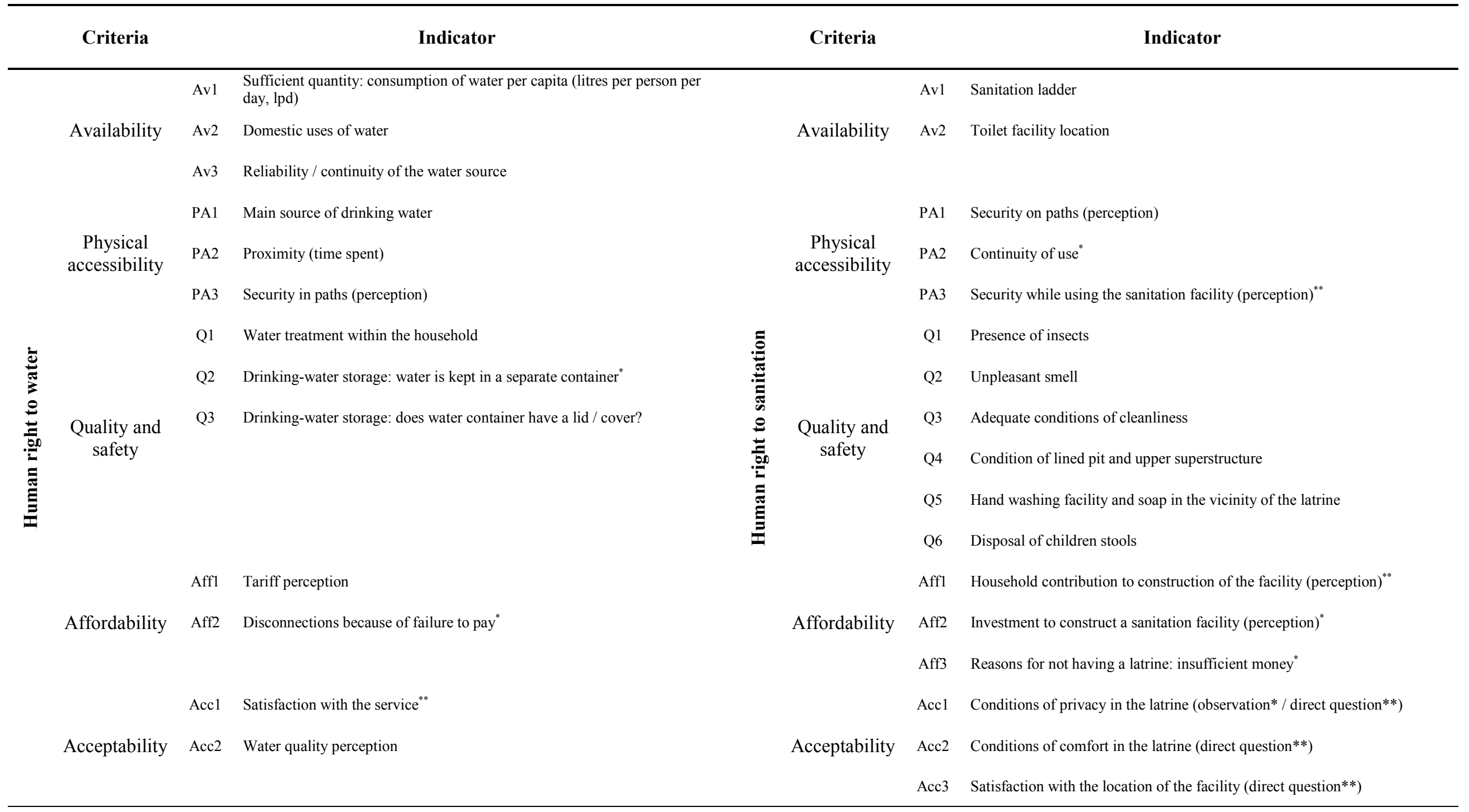

*Only applies to Manhiça (Mozambique) //**Only applies to San Sebastián de Yalí (Nicaragua) 


\subsection{Assessment of expert opinion through the AHP method}

The AHP developed by Saaty (1980) is a multi-criteria decision-making technique based on the organization of the decision-making problem in a hierarchical structure, resulting in a ranked relative importance of its elements by using expert judgements (Saaty 1994).The main reasons for selecting AHP as the weighting method are that it is: a) a flexible tool; b) simple to use and easy to understand by the stakeholders, thus allowing potential gaps between academic tools and stakeholders to be bridged; and c) a commonly used methodology in the composite indicators literature when dealing with participatory tools. We extensively employed this tool in the water sector (Bao et al. 2013; Gallego-Ayala and Juizo 2014; Ruiz-Villaverde et al. 2013).

AHP allows the relative importance of the criteria under evaluation (the normative criteria of the HRWS in this case study) to be identified using a pairwise comparison system. The expert opinion is used in the systematic evaluation of the criteria analysed using the pairwise comparison. At this stage, the experts are asked to compare pairs of criteria in a straightforward process, to identify the more important criteria and to determine how much more important they are relative to the other criteria. To facilitate this decision-making process and to potentially obtain more consistent judgments from the experts, each expert received a definition of the criteria under evaluation as well as a 1-to-9 linear scale about how to express the importance of one criterion with respect to the others. The information gathered in the pairwise comparison exercise was then used to build the so-called Saaty matrices. The eigenvector method was used in the Saaty matrices to derive the weights for the different criteria (Saaty 1980). It should be highlighted that AHP was originally developed for individual decision-making; however, this technique has been widely used over the years for group decision. Thus, AHP was implemented by using the Aggregation of Individual Judgements approach (Forman and Peniwati 1998) to derive the weights of the expert opinion. For further information about the mathematical formulation of the AHP see Saaty (1980).

Taking into consideration the complexity of the content of HRWS, both in their criteria and indicators, we decided to limit the use of expert opinion to the five normative criteria that may be considered as evaluating levels of service according to the HRWS conceptual framework. The AHP technique was carried out by three different groups of water and sanitation experts: one group with working experience in Mozambique, another group with working experience in Nicaragua, and a group of international experts. A questionnaire structured following the standard AHP pairwise comparison system was distributed among the water and sanitation experts to implement the AHP. Experts who participate in the survey were selected taking into account both their familiarity with the HRWS and their knowledge of the WASH sector at national and international levels. The questionnaire included support tools (definition of the normative criteria of the HRWS and the AHP basic scale for the pairwise comparison) to facilitate decision-making of the factors evaluated.

A total of 60 questionnaires were handed out to a representative sample of water and sanitation experts (with 20 each for the Mozambique, Nicaragua, and international groups), who had a wide array of backgrounds 
and worked for different types of institutions (public sector, private sector, academia, and international cooperation). The number of experts interviewed is in line with the sample size used by other researchers when applying AHP to identify expert opinion in a given area (Gómez-Limón and Atance 2004; Qureshi and Harrison 2003; Saisana and Saltelli 2008). Thus, the sample size used followed the accepted standards when applying AHP in expert opinion and can be considered representative, bearing in mind the limited number of experts in HRWS. A total of 37 valid questionnaires were obtained: 12 from Mozambique (with $60 \%$ of questionnaires returned), 11 from Nicaragua (55\% of questionnaires returned), and 14 from international experts ( $70 \%$ of questionnaires returned). The main idea behind the use of three separate groups of experts was to compare any potential differences in the relative importance of the HRWS criteria among the different groups of experts; in fact, the present study also examines whether the local context can affect the relative importance of the HRWS criteria when monitoring the sector.

\subsection{Construction of aggregated indicators}

In terms of method and technique, index construction relies on a step-by-step procedure initially suggested by OECD-JRC (2008), which was adopted by Giné Garriga and Pérez-Foguet (2010) to estimate a Water Poverty Index (WPI), and which was subsequently applied to other conceptual frameworks (Flores et al. 2013; Giné Garriga and Pérez Foguet 2013; Pérez-Foguet and Giné Garriga 2011). In brief, index construction involves three key stages: i) selection and combination of key indicators into their corresponding subindices, using an equal and dimensionless numeric scale; ii) determination of weights for each subindex and their aggregation to yield an overall index; and iii) dissemination of achieved results.

The first stage involves a revision of survey data and selection of indicators, which are then classified according to the dimensions described in the conceptual framework. As mentioned in the previous section, we opted to exploit the normative criteria of HRWS when defining the dimensions of the index. Therefore, water and sanitation indicators have been classified in five different categories-availability, physical accessibility, quality and safety, affordability and acceptability - by following the HRWS theoretical framework. While defining the set of indicators included in the study, we followed some basic rules: i) availability (measurable at reasonable cost), ii) simplicity (simply defined and easily understood by those who are likely to use it), and iii) accuracy (supported by reliable information). In total, a set of 30 indicators (13 indicators to measure the right to water, and 17 indicators to measure the right to sanitation) were selected to assess the different dimensions (Table 3). Typically, data are represented on different scales (e.g., percentage of households [HHs] reporting "yes", distance-to-source in meters, water consumption in litres per capita, and so forth), and they therefore have to be normalized prior to their analyses. For each parameter, we assigned a score between 0 and 1, where 1 represents the best performance and 0 the worst case scenario. For this, we opted for a categorical normalisation (Freudenberg 2003; OECD-JRC 2008), in which indicators are divided in no more than four scale scores $(0,0.33,0.66$, and 1$)$, since most indicators were initially assessed in a qualitative way. After data normalisation, the index dimensions are calculated as 
the arithmetic average of raw indicators ${ }^{1}$. The rationale for using an additive function at this aggregation level is that the focus of the tool is on the components rather than the single indicators. There is consensus about human rights criteria but not about which indicators should be in place to assess such rights. For this reason, compensability between indicators is not an issue of concern at this aggregation level. Numerically, sub-indexes for both water and sanitation can be formulated as:

$$
A v, P A, Q, A f f, A c c=\frac{\sum_{i=1,2,3 \ldots} X_{i}}{n_{T}}
$$

where $A v, P A, Q, A f, f$ and $A c c$ are the values of each criteria (for both water and sanitation) for a particular household, $\mathrm{Xi}$ refers to indicator $\mathrm{i}$ of the criterion, and $\mathrm{n}_{\mathrm{T}}$ is the total number of indicators that were considered for each criteria.

Next, the different dimensions of the index are aggregated into one single value. Two major issues need to be addressed: i) the choice of weights should reflect the relative importance of each of the dimensions, and ii) the aggregation function should be consistent with the theoretical framework. For weight assignment (described in the previous section), three different approaches have been adopted: i) statistical weights based on multivariate techniques; ii) weights based on expert opinion - the AHP technique was applied to assess the relative influence of the dimensions in the final index; and iii) equal weights. With regard to the aggregation process, it is noteworthy that linear aggregations allow compensability among the different dimensions (Munda and Nardo 2005; OECD-JRC 2008), which is not desirable in this study as different rights-based criteria are equally legitimate (United Nations 2002). We therefore opted to use a weighted multiplicative function, which is also a common aggregation method for constructing composite indicators (Blancas et al. 2013; Giné Garriga and Pérez-Foguet 2010; Munda 2012; Zhou et al. 2010)². Numerically, the two indices can be formulated as:

$$
W I=\prod_{i=A v, P A, Q, A f f, A c c} X_{i}^{w_{i}} S I=\prod_{i=A v, P A, Q, A f f, A c c} X_{i}^{w_{i}}
$$

where WI and SI are the values of the water and sanitation index for a particular household, Xi refers to dimension $\mathrm{i}$ of the index, and $\mathrm{w}_{\mathrm{i}}$ is the weight applied to that dimension.

The final step relates to visualization of the achieved results. Composite indicators must be able to quickly and accurately communicate a picture of the context in which the services are delivered. Indeed, it is necessary to foster active dissemination of the results to decision makers, stakeholders, and the civil society,

\footnotetext{
${ }^{1}$ In some cases, one positive or negative answer to a given indicator led to other indicators not being assessed. For instance, those households practicing open defecation were not evaluated against the other sanitation criteria - they were categorized as "not applicable".

${ }^{2}$ In those cases where one household had no data to assess one or more specific dimensions, a weighted mean of other dimensions was calculated to assess the final index value.
} 
paying special attention to involve them in the process. This is particularly relevant when considering a human rights-based approach (Jonsson, 2003), which is the approach of interventions on the ground where the research took place. Particular attention should be given to working according to the principles of participation, accountability, and non-discrimination, as proposed elsewhere (United Nations, 2002).

\subsection{Regional settings}

For this research, we selected two different but complementary settings, namely, the municipality of Manhiça (Mozambique) and the municipality of San Sebastián de Yalí (Nicaragua), as initial case studies to test the applicability and validity of the proposed methodology. Mozambique and Nicaragua were selected as pilot study countries as they are representative for the Sub-Saharan African and Latin American contexts, respectively, and both have low values on the Human Development Index (HDI) for their regions, of HDI 0.416 for Mozambique and HDI 0.631 for Nicaragua (UNDP 2015). Differences in and similarities between global water and sanitation indicators between the two countries are discussed in section 3 .

In Mozambique, a large proportion of the population still does not have access to safe water and sanitation facilities. According to official data (Joint Monitoring Programme 2015), only half (51\%) of the population uses improved sources of drinking water, and only one of five (21\%) households have access to adequate sanitation facilities. The situation in rural areas is much below the national average, with $37 \%$ and $10 \%$ of the population with access to improved sources of water and adequate sanitation facilities. In addition, regional disparities exist, as large numbers of rural districts do not reach these coverage ratios, and inequalities between rich and poor show that vulnerable populations are being left behind-for instance, the national average masks an open defecation prevalence of $96 \%$ among the rural poor. In all, diseases related to water and sanitation, arising from lack of access to safe water, poor drinking water quality, inadequate sanitation facilities, and poor hygiene practices, contribute to a high mortality of children under five, with an estimated 10,700 death of under-five children annually (WSP 2012). The Mozambican case study is based on research carried out in the Municipality of Manhiça (with data collected in 2012), which is located in the Manhiça District, Maputo Province, in southern Mozambique. Administratively, the municipality has 18 inhabited bairros (neighbourhoods) and covers a rough area of $250 \mathrm{~km}^{2}$. According to the local estimates, the population roughly totals 61,000 distributed in peri-urban and rural contexts.

Although the official data for Nicaragua (Joint Monitoring Programme 2015) show that its situation is considerably better than that of Mozambique, its coverage levels are nevertheless among the lowest in Latin America and the Caribbean region. About $87 \%$ of the population uses improved drinking water sources, and $68 \%$ uses improved sanitation facilities. As in the majority of countries, the situation in rural areas is below the national average, where $69 \%$ and $56 \%$ of population have access to improved sources of water and adequate sanitation facilities, respectively. However, on a more positive note, the urban-rural disparity in access to drinking water and sanitation has-slowly_decreased since 1990. According to results from the Rapid Assessment of Drinking-Water Quality (RADWQ) carried out in the country, there is a real problem with the quality of drinking water, as arsenic contamination is far more widespread than has been assumed. 
Also, most of the examined water supplies were contaminated with faecal coliforms or thermotolerant streptococci (World Health Organization and UNICEF 2010). Regional disparities between Caribbean, Central, and Pacific regions, gender discrimination, and inequalities between the rich and the poor are issues of concern for human rights activists (ONGAWA - Engineering for Human Development 2015). The Nicaraguan case study is based on field research conducted in the San Sebastian de Yalí Municipality that is situated in the Jinotega department in the central northern region of the country. According to last official statistics (INIDE 2005), about 27,000 people live in this territory, with approximately 22,500 within 74 dispersed rural communities that are distributed over 6 districts and cover an area of $402 \mathrm{~km}^{2}$. The case study is focused on rural human settlements.

The two case studies were implemented similarly in terms of data collection and data analysis, although each one adopted particular features, which are briefly summarized in Table 4. A detailed description of the survey protocol and sampling issues is provided elsewhere (Flores Baquero et al. 2015; Giné Garriga et al. 2013)

Table 4. Summary of key information about data collection in both regional settings

\begin{tabular}{|c|c|}
\hline Case Study & Key features \\
\hline $\begin{array}{l}\text { Manhiça, } \\
\text { Mozambique }\end{array}$ & $\begin{array}{l}\text { - Sampling Plan (at bairro level): } \alpha=0.05 ; \mathrm{D}=2 ; \mathrm{d}= \pm 0.15 ; \mathrm{n}(\mathrm{min})=86 . \text { In total, } 1,229 \\
\text { households were surveyed } \\
\text { - The HH checklist included } 82 \text { questions related to water, sanitation, and domestic hygiene } \\
\text { issues ( } 45 \text { minutes per HH) } \\
\text { - The field team included three staff from UPC ( } 1 \text { fully involved), } 3 \text { technicians from the } \\
\text { Vereação para Urbanização, Construção, Água e Saneamento (partially involved), } 14 \text { staff from } \\
\text { a consultancy firm, and } 1 \text { person from each visited village. Field work was completed in } 29 \\
\text { days. }\end{array}$ \\
\hline $\begin{array}{l}\text { San Sebastián } \\
\text { de Yalí, } \\
\text { Nicaragua }\end{array}$ & $\begin{array}{l}\text { - Sampling Plan (at community level). Each of the } 74 \text { communities was divided into two } \\
\text { subgroups: i) households not served by a community-managed water supply system, and ii) } \\
\text { households with self-provision. Field work was completed in } 44 \text { days. In total, } 1,657 \\
\text { households were surveyed } \\
\text { - The HH checklist included } 90 \text { questions related to water, sanitation, and domestic hygiene } \\
\text { issues ( } 35-45 \text { minutes per HH) } \\
\text { - Data collection was undertaken primarily by ONGAWA in collaboration with UPC-GRECDH, } \\
\text { the Municipality of San Sebastian de Yalí, and other local stakeholders. The field team included } \\
1 \text { staff from UPC (fully involved), } 1-3 \text { volunteers from ONGAWA (fully involved), } 1 \\
\text { technician from the Municipal Water and Sanitation Unit (UMAS) of the municipality of SSY, } \\
10 \text { students from a national university (UNAN-Leon), and 1-4 people from each visited village }\end{array}$ \\
\hline
\end{tabular}




\section{The relative influence of the normative content of HRWS}

In this section, the results achieved from the AHP exercise are presented and discussed. Analysis is carried out separately by groups: i) international experts, ii) experts with working experience in Mozambique; and iii) experts with working experience in Nicaragua. The results and consistency ratios differentiating these groups are summarized in Table 5. It should be highlighted that the weights obtained in the three groups studied are robust, since all the Saaty matrices obtained present a high degree of consistency (e.g. the consistency ratio for all matrices is less than 5\%; see Table 5).

Table 5. Weights of the HRWS normative criteria from the expert points of view

\begin{tabular}{lccc}
\hline Normative criteria & $\begin{array}{c}\text { International experts } \\
(\mathbf{N}=\mathbf{1 4})\end{array}$ & $\begin{array}{c}\text { Experts with working } \\
\text { experience in } \\
\text { Mozambique } \\
(\mathbf{N}=\mathbf{1 2})\end{array}$ & $\begin{array}{c}\text { Experts with working } \\
\text { experience in } \\
\text { Nicaragua } \\
(\mathbf{N}=\mathbf{1 1})\end{array}$ \\
\hline Water & $22.19(+)$ & $24.84(+)$ & $23.65(+)$ \\
Availability & $20.20(\mathrm{o})$ & $25.30(++)$ & $17.25(\mathrm{o})$ \\
Physical accessibility & $27.00(++)$ & $19.06(-)$ & $33.11(++)$ \\
Quality / safety & $20.05(-)$ & $21.15(\mathrm{o})$ & $15.10(-)$ \\
Affordability & $10.56(--)$ & $9.64(--)$ & $10.89(--)$ \\
Acceptability & & & $22.32(\mathrm{o})$ \\
\hline Sanitation & $18.63(\mathrm{o})$ & $17.30(-)$ & $22.54(+)$ \\
Availability & $18.68(+)$ & $22.47(+)$ & $26.53(++)$ \\
Physical accessibility & $30.33(++)$ & $28.70(++)$ & $12.60(--)$ \\
Quality / safety & $13.91(--)$ & $17.80(\mathrm{o})$ & $16.01(-)$ \\
Affordability & $18.45(-)$ & $13.73(--)$ & \\
Acceptability & & &
\end{tabular}

(++) Highest priority; (+) High priority; (o) Priority; (-) Low priority; (--) Lowest priority

Saaty matrix consistency ratios for: 1) international experts: water, CR $1.09 \%$, sanitation, CR $0.18 \%$; 2 )

Mozambican experts: water, CR $1.63 \%$, sanitation, CR 1.32\%; 3) Nicaraguan experts: water, CR $4.72 \%$, sanitation, CR $2.51 \%$.

For water issues, the importance of water-related criteria varies depending on the group of experts. For instance, quality issues are highly prioritized by both international and Nicaraguan experts, but they are not a priority for Mozambican experts. The fact that quality is the most critical criterion for a large part of experts is fully consistent with international concern about the necessity to better include quality issues in global monitoring (Jiménez and Pérez-Foguet 2012; Joint Monitoring Programme 2014a; Bain et al. 2012).

Physical accessibility to the water point is a major issue in Mozambique but receives less importance in Nicaragua. Interestingly, all experts agree on the importance of securing sufficient and continuous water for personal and domestic uses. In contrast, little attention is paid to acceptability issues to characterize water 
service levels. This is probably associated with two ideas: i) on the one hand, colour, odour, and taste (elements of acceptability criterion) have been included as part of quality criterion when defining human right to water normative content (United Nations 2002) and indeed, monitoring proposals to operationalize specific metrics for these normative criteria have evolved in this sense (Flores et al. 2013); ii) on the other hand, indigenous people and nomadic and traveller communities deserve a special mention when talking about culturally acceptable services. Adapting the current paradigm for water service delivery in rural areas to meet the needs of indigenous peoples is still a challenge that requires specific resources and approaches (Jiménez et al. 2014a). These requirements are not usually on the agenda and, even more, little attention has been paid to these issues in the literature (Jiménez et al. 2014a). Therefore it can be understood that the consulted experts did not prioritized acceptability criterion.

For Mozambique, availability, physical accessibility, quality, and affordability are scored very closely, ranging from $19.06 \%$ (quality) to $25.30 \%$ (physical accessibility). However, as mentioned above, quality is a major concern for Nicaraguan experts, and there is a significant quantitative leap between this criterion (33.11\%) and availability (23,65\%), the second most-weighted one. Differences in the relative importance of water quality criterion between both countries are probably associated with wide gaps in relation to access to improved water technology between countries (Mozambique, 51\%, and Nicaragua, 87\%). Mozambique's progress toward the Millennium Development Goal (MDG) target is moderate, and this may justify the vision of Mozambicans experts about the urgent need to focus on the physical accessibility criterion to measure level of service. On the other hand, Nicaragua has met the target, but there is a real problem with the quality of drinking water in the country (World Health Organization and UNICEF 2010). These two points may explain the relative importance of quality criterion considered by Nicaraguan experts.

Regarding sanitation, the expert opinions aligned for both countries as well as the international experts. It is noteworthy that quality and safety issues are a top priority for characterizing service levels. Taking into account international expert results, the gap between quality and the second most important criterion is even higher than for water. This may be due to the fact that the quality/safety criteria include sanitation as well as hygiene elements, which are a major issue of concern for Sustainable Development Goals (SDGs) (Joint Monitoring Programme 2014a), even though relevant quality issues still remain unaddressed in the present SDG proposal (Flores et al. 2015). This has implications not only from the viewpoint of health, but also from a gender perspective: facilities should be equipped for adequate menstrual hygiene management. Further priorities that should be addressed when promoting sanitation services include physical accessibility at all times to the toilet and the availability of a sufficient number of sanitation facilities within, or in the immediate vicinity of, each household. It is also remarkable that affordability and acceptability aspects are not seen by experts as core aspects of the sanitation challenge.

Comparing water and sanitation results, it is noteworthy that the relative importance of the acceptability criterion is increasing at the expense of that of affordability. The acceptability criterion in the case of sanitation incorporates specific content that distinguish it from water (privacy, dignity, and comfort elements), which in fact has been used to argue that sanitation should be recognized as a distinct right 
(United Nations 2009b). This "much richness in content" may partially explain a higher relative importance of sanitation acceptability criterion in relation to water.

At the same time, the affordability criterion is a controversial issue. Despite initial attempts to incorporate this dimension in international development goals, academics warned that it fell outside final commitments in MDGs (Langford 2010). However, it seems to be that the issue should be solved somehow in SDGs (United Nations General Assembly 2014). This historical omission can partly explain the low importance attached to it for measuring levels of service by the consulted experts. The situation for the sanitation issue is even more complex. According to JMP (2015), the world has missed the MDG sanitation target, and the current most used approaches focus on the elimination of open defecation, requiring families to construct or rehabilitate their sanitation facilities. In the last decade, these approaches have focused on changing behaviour and eliminating subsidies for construction, which have been applied in the past with little success. This might explain the low weight given to the affordability criterion by experts, although some studies show that the price of products, the different options for payment, and the economic capacity of households can be a critical issue for some rural households to improve their sanitation (Jiménez et al. 2014b)

Differences between Mozambican and Nicaraguan experts are unremarkable with respect to sanitation. Thus, there seems to be a common understanding among experts about the relative less importance of acceptability, but quality, availability, physical accessibility, and affordability are more context-based criteria. In fact, several international experts pointed out the difficulty in comparing criteria due to their context-based nature.

Finally, it is evident that the indicators proposed to be used in post-2015 monitoring are rights-sensitive, as the proposal takes into account normative criteria to monitoring improvements in service levels (Joint Monitoring Programme 2014a; United Nations General Assembly 2014). However, not all the five criteria have been considered equally, and this may have policy implications. The root causes of inadequate service level may be context-specific, and revealing these can help to design appropriate policy responses. Whereas the issues of availability, physical accessibility and quality, and safety dimensions have been adequately incorporated in the new monitoring framework, insufficient attention has been given to the affordability and acceptability criteria (Flores et al. 2015). Interestingly, weighing these criteria less heavily is consistent among international experts, according to results from this article. 


\section{Analysing the influence of weighting techniques on aggregated measures}

As mentioned in the previous section, three different approaches have been tested to determine weights for index construction: statistical weights based on multivariate techniques, weights based on expert opinion, and equal weights. Results are displayed in Table 6 for the three options and the two case studies.

To start with, each weighting system produces slightly different weights - thus, for Mozambique, the statistical solution (Principal Component Analysis, PCA) weights the water-related criteria of quality, affordability and acceptability more heavily, whilst Mozambican experts highlighted an increased influence of the availability and accessibility criteria (Table 6). Interestingly, the statistical-related weights of the two case studies show a high degree of similarity, and this is likely due to the use of same set of indicators (see Table 3). In any case, the achieved results (see Figures 1 and 2) show that the different weighting systems have remarkably little impact on either the final index values or priority rankings, which are prioritization lists of population groups based on index values. This finding is consistent with the evidence from previous studies (Giné Garriga and Pérez-Foguet 2010; OECD-JRC 2008).

Table 6. Weights based on different techniques, for Mozambique and Nicaragua

\begin{tabular}{llll|lcc}
\hline \multicolumn{1}{c}{ Criterion } & \multicolumn{3}{c}{ Weights Mozambique } & \multicolumn{3}{c}{ Weights Nicaragua } \\
& AHP & $P C A$ & Equal & AHP & PCA & Equal \\
\hline Water & & & & & & \\
Availability & 0.248 & 0.176 & 0.200 & 0.237 & 0.160 & 0.200 \\
Physical accessibility & 0.253 & 0.123 & 0.200 & 0.173 & 0.128 & 0.200 \\
Quality/safety & 0.191 & 0.232 & 0.200 & 0.331 & 0.239 & 0.200 \\
Affordability & 0.212 & 0.232 & 0.200 & 0.151 & 0.237 & 0.200 \\
Acceptability & 0.096 & 0.237 & 0.200 & 0.109 & 0.236 & 0.200 \\
\hline Sanitation & & & & & & \\
Availability & 0.173 & 0.235 & 0.200 & 0.223 & 0.212 & 0.200 \\
Physical accessibility & 0.225 & 0.232 & 0.200 & 0.225 & 0.203 & 0.200 \\
Quality/safety & 0.287 & 0.230 & 0.200 & 0.265 & 0.202 & 0.200 \\
Affordability & 0.178 & 0.137 & 0.200 & 0.126 & 0.177 & 0.200 \\
Acceptability & 0.137 & 0.166 & 0.200 & 0.160 & 0.206 & 0.200 \\
\hline
\end{tabular}

A closer look at the information provided by the indices' components allows complementary conclusions to be drawn. Histograms ${ }^{3}$ are summarized in Tables 7 and 8 for Manhiça and San Sebastián de Yalí, respectively, where all five criteria and the aggregated index (considering equal weights) are shown separately. In San Sebastián de Yalí, households were classified in two different groups: "with access to a communitarian system managed by a committee" and "with access to water based on self-supply

\footnotetext{
${ }^{3}$ The "non-applicable" and "unknown" categories have been added to the non-respondents for simplicity considerations. This category includes, for instance, those households i) practicing open defecation, ii) with no children under three, and iii) not connected to community systems managed by a committee.
} 
mechanisms". In the aggregation process from the household up to the community, households were weighted against total number of households in each of these two groups. Similarly, communities were also weighted based on total population, to yield an overall value for the municipality. In Manhiça (Mozambique), the sampling procedure was self-weighted.

Overall, the situation in both contexts is not "critical" in terms of access to water supply services. Thus, it seems that availability and physical accessibility is by-and-large adequate. Nonetheless, quality and safety issues should be addressed. A closer look shows that one of the indicators employed to assess this dimension is "household water treatment" and, remarkably, fewer than one out of ten households treat water at the point-of-use in Manhiça. This does not necessarily mean that the drinking water is not safe. The dimensions related to affordability and acceptability score considerably higher. It should be mentioned, however, that reliability of the indicators employed in the assessment of these two dimensions is questionable, which may have impacted the achieved results.

For the sanitation criterion, it is important to highlight that households practicing open defecation scored " 0 " in availability dimension (approximately $15 \%$ and $25 \%$ of HH in Manhiça and San Sebastián de Yalí, respectively). For these households, the rest of dimensions were been assessed, as explained in footnote 1. In the rest of households, i.e. where sanitation is available, adequate accessibility and continued use of the facility is largely ensured. On the other hand, toilet facilities in general are not hygienically maintained, and safety and quality issues are not adequately addressed.

Human rights are indivisible, and this is valid also for the components within them. The violation or noncompliance of one of these components implies ipso facto human rights non-compliance. Therefore, from a policy perspective, multiplicative aggregation is considered to combine dimensions, as discussed above. It is easily observed that the geometric function to aggregate dimensions considerably impact the final index values. Approximately $40 \%$ and $30 \%$ of households achieve null water index values in Manhiça and San Sebastián de Yalí, respectively. Moreover, about 1 out of 3 households achieve null values in both regional settings for the sanitation index.

Taking this argument to the level of indicators, it could be concluded that all indicators should score their maximum values to consider that human rights are being fully enjoyed. However, the proportion of households that scored maximum for all indicators is almost negligible in both regional settings (with $0.5 \%$ for both water and sanitation indices in Manhiça, and $4.2 \%$ and $1 \%$ for the water and sanitation indices, respectively, in Nicaragua). Some of the suggested indicators may have a range of values for which more than one could be considered admissible according to the human rights standards. For example, "piped water on premises" scored 1, while "other improved" categories scored 0.66 , in the PA1 indicator, but both are considered as improved sources of drinking water at the international level. Other indicators may be questionable, as mentioned above with respect to water treatment within a household. For all these reasons, an "adequate access to water and sanitation services" could be reported, from a rights perspective, if the index value is above 0.8 . Revision based on this less strict setting that considers the human rights normative 
content shows that approximately $27 \%$ and $14 \%$ of households in Manhiça have an adequate level of water and sanitation services, respectively. Similarly, only 13\% and 17\% of households in San Sebastián de Yalí report adequate access to water and sanitation, respectively. 
Table 7. Histograms (number of families) for each criterion and composite indicator. Water (top) and sanitation (bottom). Manhiça (Mozambique) case study.

\begin{tabular}{|c|c|c|c|c|c|c|c|c|c|c|c|c|}
\hline & \multicolumn{2}{|c|}{ Availability } & \multicolumn{2}{|c|}{ Physical Accessibility } & \multicolumn{2}{|c|}{ Quality and Safety } & \multicolumn{2}{|c|}{ Affordability } & \multicolumn{2}{|c|}{ Acceptability } & \multicolumn{2}{|c|}{ WaterIndex_Equal } \\
\hline & Total & $(\%)$ & Total & $(\%)$ & Total & (\%) & Total & $(\%)$ & Total & $(\%)$ & Total & $(\%)$ \\
\hline 0 & 0 & 0,0 & 0 & 0,0 & 456 & 37,1 & 11 & 0,9 & 16 & 1,3 & 473 & 38,5 \\
\hline $0-0,2$ & 2 & 0,2 & 0 & 0,0 & 0 & 0,0 & 0 & 0,0 & 0 & 0,0 & 0 & 0,0 \\
\hline $0,2-0,4$ & 52 & 4,2 & 16 & 1,3 & 197 & 16,0 & 15 & 1,2 & 0 & 0,0 & 0 & 0,0 \\
\hline $0,4+0,6$ & 210 & 17,1 & 95 & 7,7 & 18 & 1,5 & 107 & 8,7 & 0 & 0,0 & 11 & 0,9 \\
\hline $0,6-0,8$ & 572 & 46,5 & 635 & 51,7 & 508 & 41,3 & 2 & 0,2 & 0 & 0,0 & 347 & 28,2 \\
\hline $0,8-1$ & 115 & 9,4 & 78 & 6,3 & 0 & 0,0 & 362 & 29,6 & 0 & 0,0 & 392 & 31,9 \\
\hline 1 & 278 & 22,6 & 405 & 33,0 & 50 & 4,1 & 726 & 59,4 & 1212 & 98,7 & 6 & 0,5 \\
\hline No data / Not applicable & 0 & & 0 & & 0 & & 6 & & 1 & & 0 & \\
\hline \multirow[t]{3}{*}{ Total HH } & 1229 & & 1229 & & 1229 & & 1229 & & 1229 & & 1229 & \\
\hline & \multicolumn{2}{|c|}{ Availability } & \multicolumn{2}{|c|}{ Physical Accessibility } & \multicolumn{2}{|c|}{ Quality and Safety } & \multicolumn{2}{|c|}{ Affordability } & \multicolumn{2}{|c|}{ Acceptability } & \multicolumn{2}{|c|}{ Sanitation Index_Equal } \\
\hline & Total & $(\%)$ & Total & $(\%)$ & Total & $(\%)$ & Total & $(\%)$ & Total & $(\%)$ & Total & $(\%)$ \\
\hline 0 & 175 & 14,2 & 0 & 0,0 & 1 & 0,1 & 155 & 17,6 & 117 & 11,1 & 430 & 35,0 \\
\hline $0-0,2$ & 9 & 0,7 & 0 & 0,0 & 204 & 19,4 & 0 & 0,0 & 0 & 0,0 & 0 & 0,0 \\
\hline $0,2-0,4$ & 6 & 0,5 & 0 & 0,0 & 364 & 34,5 & 0 & 0,0 & 694 & 65,8 & 11 & 0,9 \\
\hline $0,4+0,6$ & 707 & 57,5 & 9 & 0,9 & 220 & 20,9 & 0 & 0,0 & 0 & 0,0 & 501 & 40,8 \\
\hline $0,6-0,8$ & 7 & 0,6 & 0 & 0,0 & 72 & 6,8 & 719 & 81,8 & 0 & 0,0 & 111 & 9,0 \\
\hline $0,8-1$ & 261 & 21,2 & 0 & 0,0 & 98 & 9,3 & 0 & 0,0 & 0 & 0,0 & 170 & 13,8 \\
\hline 1 & 64 & 5,2 & 1045 & 99,1 & 95 & 9,0 & 5 & 0,6 & 243 & 23,1 & 6 & 0,5 \\
\hline No data / Not applicable & 0 & & 175 & & 175 & & 350 & & 175 & & 0 & \\
\hline Total HH & 1229 & & 1229 & & 1229 & & 1229 & & 1229 & & 1229 & \\
\hline
\end{tabular}


Table 8.Histograms (number of families) for each criterion and composite indicator. Water (top) and sanitation (bottom). San Sebastián de Yalí (Nicaragua) case study.

\begin{tabular}{|c|c|c|c|c|c|c|c|c|c|c|c|c|}
\hline & \multicolumn{2}{|c|}{ Availability } & \multicolumn{2}{|c|}{ Physical Accessibility } & \multicolumn{2}{|c|}{ Quality and Safety } & \multicolumn{2}{|c|}{ Affordability } & \multicolumn{2}{|c|}{ Acceptability } & \multicolumn{2}{|c|}{ Water Index_Equal } \\
\hline & Total & $(\%)$ & Total & $(\%)$ & Total & $(\%)$ & Total & $(\%)$ & Total & $(\%)$ & Total & (\%) \\
\hline 0 & 8 & 0,5 & 13 & 0,8 & 357 & 21,6 & 60 & 3,7 & 101 & 6,6 & 495 & 29,9 \\
\hline $0-0,2$ & 42 & 2,5 & 11 & 0,7 & 0 & 0,0 & 0 & 0,0 & 23 & 1,5 & 0 & 0,0 \\
\hline $0,2-0,4$ & 126 & 7,6 & 83 & 5,0 & 3 & 0,2 & 0 & 0,0 & 42 & 2,8 & 2 & 0,1 \\
\hline $0,4+0,6$ & 178 & 10,8 & 115 & 6,9 & 1014 & 61,2 & 0 & 0,0 & 9 & 0,6 & 82 & 5,0 \\
\hline $0,6-0,8$ & 513 & 31,1 & 701 & 42,3 & 10 & 0,6 & 309 & 18,8 & 124 & 8,1 & 624 & 37,7 \\
\hline $0,8-1$ & 60 & 3,6 & 129 & 7,8 & 0 & 0,0 & 0 & 0,0 & 493 & 32,4 & 442 & 26,7 \\
\hline 1 & 725 & 43,9 & 604 & 36,5 & 272 & 16,4 & 1274 & 77,5 & 731 & 48,0 & 11 & 0,7 \\
\hline No data / Not applicable & 4 & & 0 & & 0 & & 13 & & 133 & & 0 & \\
\hline \multirow[t]{3}{*}{ Total HH } & 1656 & & 1656 & & 1656 & & 1656 & & 1656 & & 1656 & \\
\hline & \multicolumn{2}{|c|}{ Availability } & \multicolumn{2}{|c|}{ Physical Accessibility } & \multicolumn{2}{|c|}{ Quality and Safety } & \multicolumn{2}{|c|}{ Affordability } & \multicolumn{2}{|c|}{ Acceptability } & \multicolumn{2}{|c|}{ Sanitation Index_Equal } \\
\hline & Total & (\%) & Total & $(\%)$ & Total & $(\%)$ & Total & (\%) & Total & (\%) & Total & $(\%)$ \\
\hline 0 & 413 & 25,1 & 39 & 3,2 & 27 & 2,2 & 95 & 9,7 & 24 & 2,0 & 576 & 35,0 \\
\hline $0-0,2$ & 0 & 0,0 & 0 & 0,0 & 285 & 23,0 & 0 & 0,0 & 0 & 0,0 & 0 & 0,0 \\
\hline $0,2-0,4$ & 9 & 0,5 & 0 & 0,0 & 377 & 30,4 & 0 & 0,0 & 96 & 7,8 & 5 & 0,3 \\
\hline $0,4+0,6$ & 49 & 3,0 & 295 & 23,9 & 261 & 21,1 & 0 & 0,0 & 1 & 0,1 & 181 & 11,0 \\
\hline $0,6-0,8$ & 81 & 4,9 & 0 & 0,0 & 174 & 14,0 & 783 & 79,9 & 282 & 23,0 & 574 & 34,9 \\
\hline $0,8-1$ & 131 & 8,0 & 0 & 0,0 & 45 & 3,6 & 0 & 0,0 & 0 & 0,0 & 294 & 17,9 \\
\hline 1 & 961 & 58,5 & 898 & 72,9 & 70 & 5,6 & 102 & 10,4 & 823 & 67,1 & 16 & 1,0 \\
\hline No data / Not applicable & 12 & & 424 & & 417 & & 676 & & 430 & & 10 & \\
\hline Total HH & 1656 & & 1656 & & 1656 & & 1656 & & 1656 & & 1656 & \\
\hline
\end{tabular}


Fig. 1. Comparisons of water (top) and sanitation (bottom) indices (left) and rankings (right). Manhiça (Mozambique) case study.
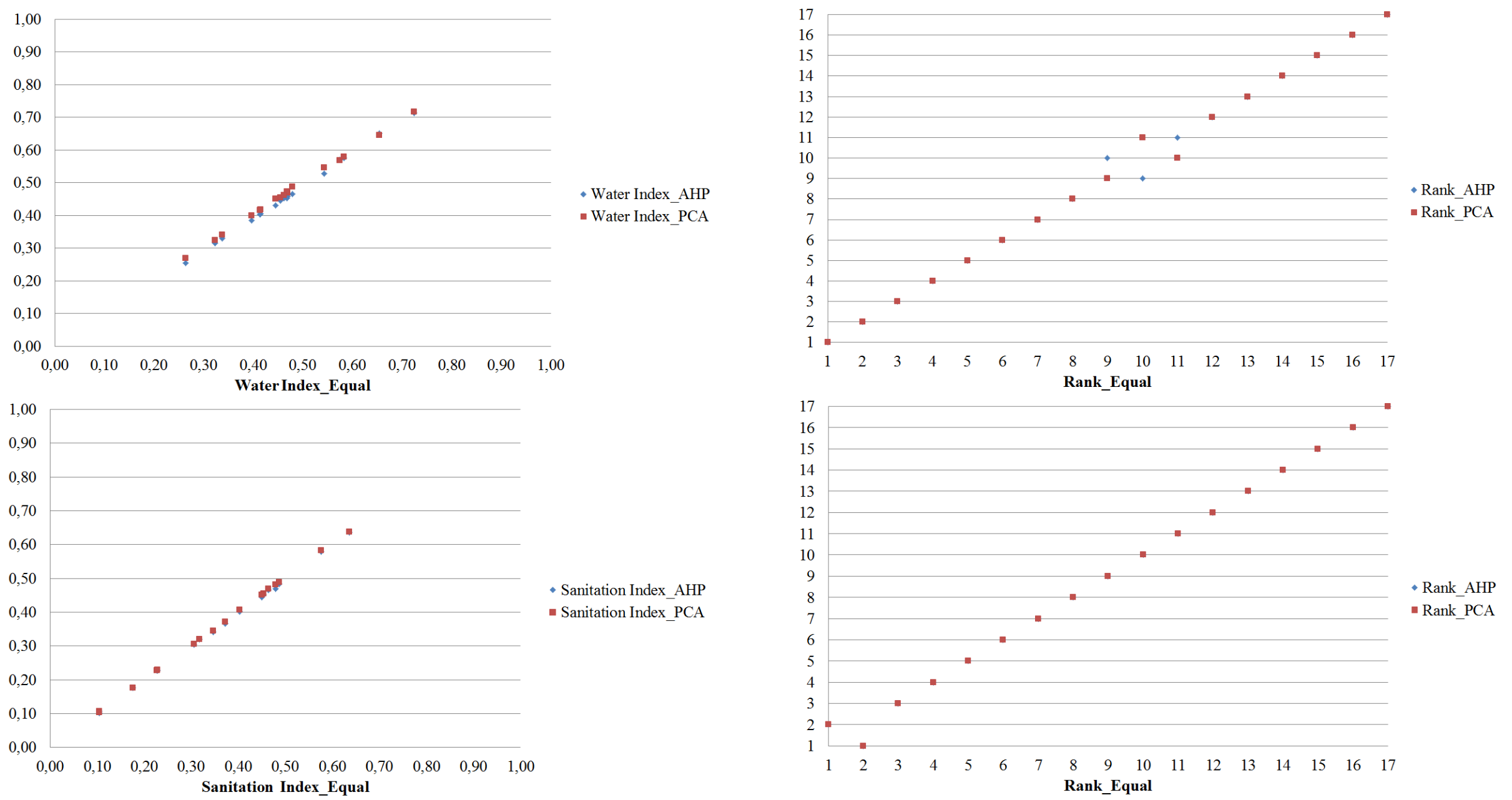
Fig. 2. Comparisons of water (top) and sanitation (bottom) indices (left) and rankings (right). San Sebastián de Yalí (Nicaragua) case study.
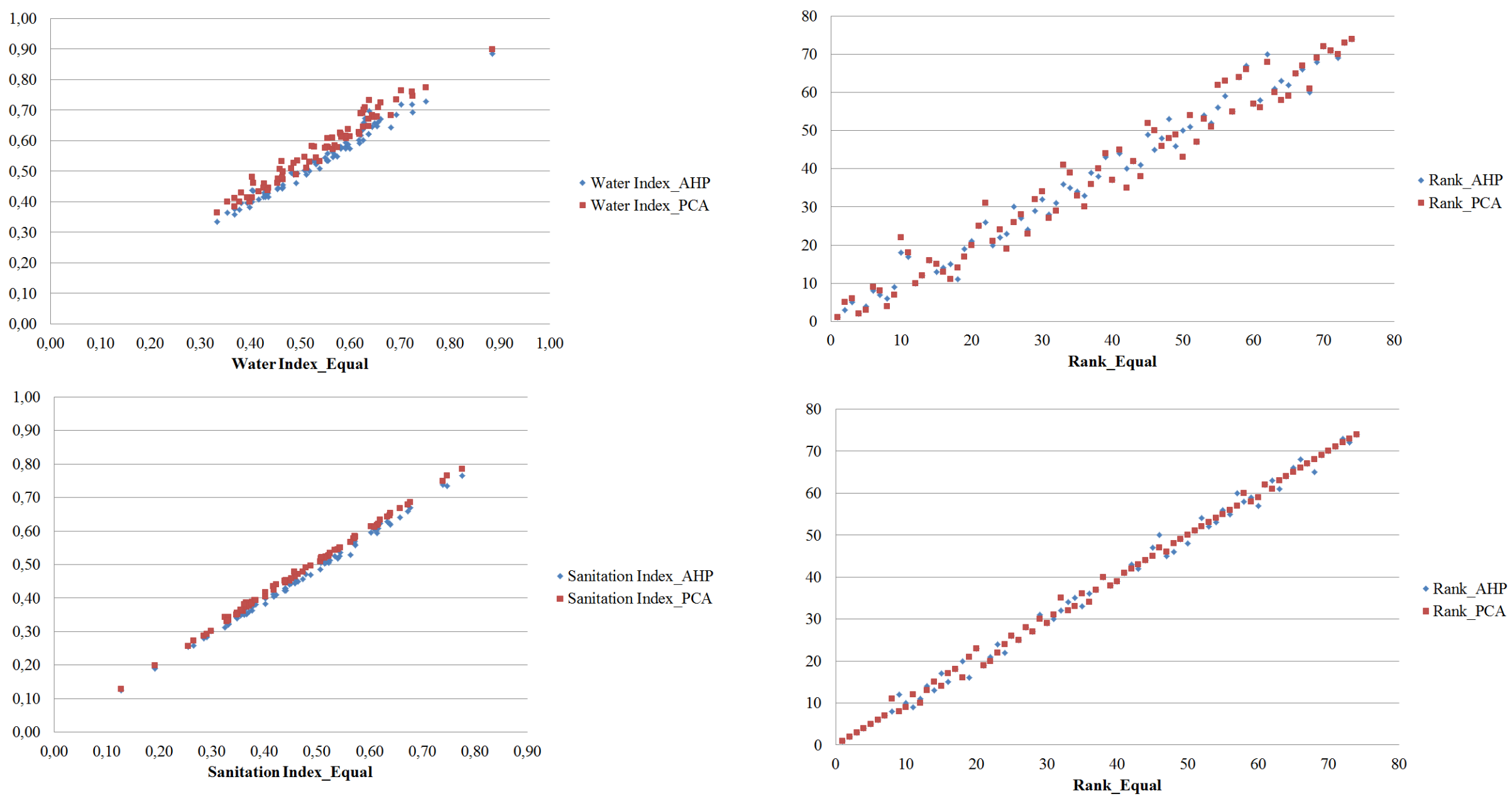


\section{Conclusions}

The human rights framework influences the water and sanitation sector at the international level, but the definition of specific metrics is at a very early stage and is still underdeveloped. It is essential to move forward with specific initiatives that interpret and operationalize their metrics, in which relevant challenges have been pointed out. Therefore, theoretical and methodological approaches have been proposed in the article with the aim of addressing the main challenges.

The first challenge is related to how to measure each dimension of both rights. This study deepens the understanding of the HRWS normative content through the operationalization of their definition into specific metrics, which can be very useful to characterize the level of these services from a rights perspective. Providing the composition of each criterion from a practitioner point-of-view, as well as a short list of key indicators to assess them, represent relevant steps forward to address the essential challenge to shift the discussion from a legal and conceptual framework to a practical one.

Secondly, the AHP technique emerges as an interesting alternative to gain more knowledge about public opinion on the relative importance of human rights normative criteria used to assess levels of service. Some of the consulted experts highlighted the fact that human rights, as well as the components that make them up, are indivisible, such that it is no single element can be identified as "the" most important one, as they all are important. However, other international experts have pointed out that context should play a critical role when comparing pairs of criteria. Even more, according to the HRWS framework, it is critical to remember that specific metrics cannot be determined in abstract and to assure that they are flexible enough to be contextually relevant. In any event, the differences in the relative importance of the HRWS criteria can be explained by the context of the country. Furthermore, the weights obtained in the three expert groups are robust, as the obtained Saaty matrices are highly consistent with each other, revealing that the methodology is easy to understand by the stakeholders. For these reasons, we conclude that this method allows appropriate tools to assess the delivery of WASH services to be constructed taking into account a rights perspective and adapted to local level contexts.

The empirical findings reveal that experts attribute a different relative importance to each HRWS normative criterion. Indeed, there are not only differences between the different normative criteria but also between the three expert groups. The differences in the relative importance given to the HRWS criteria can be explained by the particularities of the local context, with experts placing more importance on those criteria that correspond with main WASH-related problems of each country. It is relevant to note that those criteria considered as less important by national and international experts coincide with the HRWS criteria that have received less attention during the international consultative process within the WASH sector to develop proposals for goals, targets, and indicators for monitoring SDGs.

Finally, according to adequate procedures to construct a composite indicator, this research shows that weighting techniques only have a limited influence on aggregated measures. Thus, their influence on decision-making is likewise reduced. The main policy implications of this research are related to the 
indicators proposed to measure certain HRWS criteria, which could be taken into account at the international level to be fully consistent with human rights from a right holders' perspective. Finally, the methodology has a great potential to tailor specific WASH service level metrics to local contexts considering the HRWS normative content.

\section{ACKNOWLEDGEMENTS}

The authors would like to thank all families who participated in the study. Further thanks go to ONGAWAEngineering for Human Development, San Sebastián de Yalí Municipality, Ministry of Health (MINSA), and students from the Universidad Nacional Autónoma de Nicaragua (UNAN-León) in Nicaragua, and to the the Municipality of Manhiça, for their valuable contribution during field work, in Mozambique. This study was mainly funded by the Centre de Cooperació per al Desenvolupament (Universitat Politècnica de Catalunya) [references 0010-2011, 0014-2012, 0001-2013] and the Agencia Española de Cooperación Internacional para el Desarrollo [references 11-CAP2-1562 and 07-CO-068]. We also acknowledge the participation of thirty-seven anonymous experts in the study. 


\section{REFERENCES}

AQUAFED (2014) Human Right to Safe Drinking Water and Sanitation. The international Federation of Private Water Operators, http://www.aquafed.org/page-5-59.html\#7.

BAO, P. C., ARAMAKI T \& HANAKI K (2013) Assessment of stakeholders' preferences towards sustainable sanitation scenarios. Water and Environment Journal, 27, 58-70. doi:10.1111/j.17476593.2012.00327.x

BLANCAS F.J., CONTRERAS, I. \& RAMÍREZ-HURTADO J.M (2013) Constructing a composite indicator with multiplicative aggregation under the objective of ranking alternatives. Journal of the Operational Research Society, 64, 668-678. doi:10.1057/jors.2012.90

BOOYSEN, F. (2002) An overview and evaluation of composite indices of development. Social Indicators Research, 59, 115-151. doi:10.1023/A:1016275505152

BRYAN B.A., GRANDGIRARD, A. \& WARD J.R. (2010) Quantifying and Exploring Strategic Regional Priorities for Managing Natural Capital and Ecosystem Services Given Multiple Stakeholder Perspectives. Ecosystems, 13, 539-555. doi:10.1007/s10021-010-9339-0

COHRE WATERAID COSUDE AND UN-HABITAT (2008) Sanitation: A Human rights imperative. IN CENTER ON HOUSING RIGHTS AND EVICTIONS. RIGHT TO WATER PROGRAMME (Ed.). Geneve.

CHO, D., OGWANG, T. \& OPIO, C. (2010) Simplifying the Water Poverty Index. Social Indicators Research, 97, 257-267. doi:10.1007/s11205-009-9501-2

DUKE J.M. \& AULL-HYDEB R (2002) Identifying public preferences for land preservation using the analytic hierarchy process. . Ecological Economics 42, 131-145. doi:10.1016/S0921$8009(02) 00053-8$

ESTY, D. C. \& PORTER, M. E. (2005) National environmental performance: an empirical analysis of policy results and determinants. Environment and Development Economics, 10, 391-434. http://digitalcommons.law.yale.edu/fss_papers/430

FEITELSON, E. \& CHENOWETH, J. (2002) Water poverty: towards a meaningful indicator. Water Policy, 4, 263-281. doi:10.1016/S1366-7017(02)00029-6

FLORES BAQUERO, O., JIMÉNEZ FDEZ. DE PALENCIA, A. \& PÉREZ-FOGUET, A. (2015) Measuring disparities in access to water based on the normative content of the human right. Social Indicators Research, in press. doi: 10.1007/s11205-015-0976-8.

FLORES, O., JIMÉNEZ, A. \& PÉREZ-FOGUET, A. (2013) Monitoring access to water in rural areas based on the human right to water framework: A local level case study in Nicaragua. International Journal of Water Resources Development, 29, 605-621. doi: 10.1080/07900627.2012.757017

FLORES, O., JIMÉNEZ, A. \& PÉREZ-FOGUET, A. (2015) Reporting progress on Human Right to Water and Sanitation through UN water global monitoring mechanisms. Journal of Water, Sanitation and Hygiene for Development, 5, 310-321. doi: 10.2166/washdev.2015.151

FORMAN, E. \& PENIWATI, K. (1998) Aggregating individual judgments and priorities with the analytic hierarchy process. European journal of operational research, 108, 165-169. doi:10.1016/S03772217(97)00244-0

FREUDENBERG, M. (2003) Composite Indicators of Country Performance: a critical assessment., Paris, OECD Publishing. 
GALLEGO-AYALA, J., DOS SANTOS-DIMENE, C., MUNHEQUETE, A. \& AMOS, R. (2014) Assessing the performance of urban water utilities in Mozambique using a water utility performance index. Water SA, 40, 665-675. doi: 10.4314/wsa.v40i4.12

GALlegO-AYAlA, J. \& JUIZO, D. (2012) Performance evaluation of River Basin Organizations to implement integrated water resources management using composite indexes. Journal of Physics and Chemistry of the Earth, 50-52, 205-216. doi: 10.1016/j.pce.2012.08.008

GALLEGO-AYALA, J. \& JUIZO, D. (2014) Integrating stakeholders' preferences into water resources management planning in the Incomati river. Water Resources Management 28, 527-540. doi: $10.1007 / \mathrm{s} 11269-013-0500-3$

GINÉ GARRIGA, R., JIMÉNEZ, A. \& PÉREZ FOGUET, A. (2013) Water-sanitation-hygiene mapping: An improved approach for data collection at local level. Science of the Total Environment, 463-464, 700-711. doi:10.1016/j.scitotenv.2013.06.005

GINÉ GARRIGA, R. \& PÉREZ-FOGUET, A. (2010) Improved method to calculate a Water Poverty Index at local scale. Journal of Environmental Engineering, 136, 1287-1298. doi: 10.1061/(ASCE)EE.1943-7870.0000255

GINÉ GARRIGA, R. \& PÉREZ FOGUET, A. (2013) Unravelling the Linkages Between Water, Sanitation, Hygiene and Rural Poverty: The WASH Poverty Index. Water Resources Management, 27, 15011515. doi: 10.1007/s11269-012-0251-6

GÓMEZ-LIMÓN, J. A. \& ATANCE, I. (2004) Identification of public objectives related to agricultural sector support. Journal of Policy Modeling, 26, 1045-1071. doi:10.1016/j.jpolmod.2004.07.005

GÓMEZ-LIMÓN JA. \& SANCHEZ-FERNANDEZ G. (2010) Empirical evaluation of agricultural sustainability using composite indicators. Ecological Economics, 69, 1062-1075. doi:10.1016/j.ecolecon.2009.11.027

GROŠELJ, P., HODGES, D. G. \& STIRN L.Z. (2015) Participatory and multi-criteria analysis for forest (ecosystem) management: A case study of Pohorje, Slovenia. Forest Policy and Economics (in press). doi:10.1016/j.forpol.2015.05.006

HAJKOWICZ, S. (2006) Multi-attributed environmental index construction. Ecological Economics, 57, 122139. doi:10.1016/j.ecolecon.2005.03.023

INIDE (2005) Censo 2005. Instituto Nacional de Información para el Desarrollo. Retrived from http://www.inide.gob.ni/.

IRUJO, A. E. (2007) The Right to Water. International Journal of Water Resources Development, 23, 267 283. doi: $10.1080 / 07900620601182968$

JEMMALI, H. \& SULLIVAN, C. A. (2014) Multidimensional Analysis of Water Poverty in MENA Region: An Empirical Comparison with Physical Indicators. Social Indicators Research, 115, 253-277. doi: $10.1007 / \mathrm{s} 11205-012-0218-2$

JIMÉNEZ, A., CORTOBIUS, M. \& KJELLÉN, M. (2014) Water, sanitation and hygiene and indigenous peoples: a review of the literature. Water International, 39, 277-293. doi: $10.1080 / 02508060.2014 .903453$

JIMÉNEZ, A., MTANGO F. \& CAIRNCROSS, S. (2014) What role for local government in sanitation promotion? Lessons from Tanzania. Water Policy, 16 (6), 1104-1120. doi:10.2166/wp.2014.203

JIMÉNEZ, A. \& PÉREZ-FOGUET, A. (2012) Quality and year-round availability of water delivered by improved water points in rural Tanzania: effects on coverage. Water Policy, 14, 509-523. doi: 10.2166/wp.2011.026 
JOINT MONITORING PROGRAMME (2014a) WASH targets and indicators post-2015: Recommendations from international consultations. Updated april 2014. Retrieved from http://www.wssinfo.org/fileadmin/user_upload/resources/post-2015-WASH-targets-factsheet12pp.pdf Accessed 02 January 2015.

JOINT MONITORING PROGRAMME (2015) Progress on Sanitation and Drinking-water - 2015 update and MDG assessment Geneva / New York, JMP, http://www.wssinfo.org/fileadmin/user upload/resources/JMP-Update-report-2015 English.pdf Accessed 3 November 2015.

JONSSON, U. (2003) Human Rights approach to development programming, UNICEF. Eastern and Southern Africa Regional Office.

KIM, Y., KEE, Y. \& LEE, S. J. (2015) An Analysis of the Relative Importance of Components in Measuring Community Wellbeing: Perspectives of Citizens, Public Officials, and Experts. Social Indicators Research, 121, 345-369. doi: 10.1007/s11205-014-0652-4

KOMNENIC, V., AHLERS, R. \& ZAAG, P. V. D. (2009) Assessing the usefulness of the water poverty index by applying it to a special case: Can one be water poor with high levels of access? Physics and Chemistry of the Earth, Parts A/B/C, 34, 219-224. doi:10.1016/j.pce.2008.03.005

LANGFORD, M. (2010) A Poverty of Rights: Six Ways to Fix the MDGs. IDS Bulletin, 41, 83-91. doi: 10.1111/j.1759-5436.2010.00108.x

LANGFORD, M., BARTRAM, J. \& ROAF, V. (2014) Revisiting Dignity: The Human Right to Sanitation. IN LANGFORD, M. \& RUSSELL, A. F. S. (Eds.) The Right to Water: Theory, Practice and Prospects. Cambridge, Cambridge University Press.

LEE, G. K. L. \& CHAN, E. H. W. (2008) The Analytic Hierarchy Process (AHP) Approach for Assessment of Urban Renewal Proposals. Social Indicators Research, 89, 155-168. doi: 10.1007/s11205-0079228-x

LOHANI, B. \& TODINO, G. (1984) Water Quality Index for Chao Phraya River. Journal of Environmental Engineering, 110, 1163-1176. doi: 10.1061/(ASCE)0733-9372(1984)110:6(1163)

MOLLE, F. \& MOLLINGA, P. (2003) Water Poverty Indicators: conceptual problems and policy issues. Water Policy, 5, 529-544.

MORIARTY P., SMITS S., BUTTERWORTH J. \& FRANCEYS R. (2013) Trends in Rural Water Supply: Towards a Service Delivery Approach. Water alternatives, 6, 329-349.

MUNDA, G. (2012) Choosing aggregation rules for composite indicators. Social Indicators Research, 109, 337-354. doi: 10.1007/s11205-011-9911-9

MUNDA, G. \& NARDO, M. (2005) Non-Compensatory Composite Indicators for Ranking Countries: A Defensible Setting. Ispra, Joint Research Centre European Commission.

OECD-JRC (2008) Handbook on constructing composite indicators. Methodology and user guide, París, OECD.

ONGAWA - ENGINEERING FOR HUMAN DEVELOPMENT (2015) A proposal to broadly measure the Human Right to Water and Sanitation: The reality of the rural area of Nicaragua. http://www.ongawa.org/wp-content/uploads/2015/08/ongawa-resumen-ejecutivo-BAJA.pdf.

PÉREZ-FOGUET, A. \& GINÉ GARRIGA, R. (2011) Analyzing Water Poverty in Basins. Water Resources Management, 25, 3595-3612. doi: 10.1007/s11269-011-9872-4 
QURESHI, M. E. \& HARRISON, S. R. (2003) Application of the analytic hierarchy process to riparian revegetation policy options. Small-scale Forest Economics, Management and Policy, 2, 441-458. doi: 10.1007/s11842-003-0030-6

ROAF, V., KHALFAN, A. \& LANGFORD, M. (2005) Monitoring implementation of the right to water: a framework for developing indicators. Global issue papers No. 14. Berlin, Heinrich Böll Foundation.

ROB ES BAIN, STEPHEN W GUNDRY, JIM A WRIGHT, HONG YANG, STEVE PEDLEY \& BARTRAM, J. K. (2012) Accounting for water quality in monitoring access to safe drinking water as part of the Millennium Development Goals: lessons from five countries. Bulletin of the World Health Organization, 90:228-235A.

RUIZ-VILLAVERDE A., GONZÁLEZ-GÓMEZ F. \& PICAZO-TADEO, A. J. (2013) Public choice of urban water service management: a multi-criteria approach. International Journal of Water Resources Development 29, 385-399. doi: 10.1080/07900627.2012.721668

SAATY, T. L. (1980) The Analytic Hierarchy Process, New York, McGraw Hill.

SAATY, T. L. (1994) How to make a decision: the analytic hierarchy process. Interfaces, 24, 19-43. doi: 10.1287/inte.24.6.19

SAISANA, M. \& SALTELLI, A. (2008) Expert panel opinion and global sensitivity analysis for composite indicators. IN GRAZIANI F. (Ed.) Computational Methods in Transport: Verification and Validation., Springer Berlin Heidelberg, pp.251-275.

SINGH R.K., MURTY H.R., GUPTA S.K. \& DIKSHIT A.K. (2007) Development of composite sustainability performance index for steel industry. Ecological Indicators, 7, 565-588. doi:10.1016/j.ecolind.2006.06.004

SUllivaN, C. (2002) Calculating a Water Poverty Index. World Development, 30, 1195-1210. doi:10.1016/S0305-750X(02)00035-9

Sullivan, C., MEIGH, J., GIACOMELlO, A. M. \& FEDIW, P. (2003) The Water Poverty Index: Development and application at the community scale. Natural Resources Forum, 27, 189-199. doi: $10.1111 / 1477-8947.00054$

THE DANISH INSTITUTE FOR HUMAN RIGHTS (2014) The AAAQ framework and the right to water.

UN SPECIAL RAPPORTEUR ON THE HUMAN RIGHT TO SAFE DRINKING WATER AND SANITATION (2014) Monitoring compliance with the human rights to water and sanitation (chapter 5). Realising the human rights to water and sanitation: A Handbook by the UN Special Rapporteur Catarina de Albuquerque.

UNDP (2015) Human Development Report 2015: work for human development. UNDP, New York.

UNITED NATIONS (2002) The Right to Water. E/C.12/2002/1. General Comment No. 15 of the Economic and Social Council,. New York, UN.

UNITED NATIONS (2009a) Report of the independent expert on the issue of human rights obligations related to access to safe drinking water and sanitation, Catarina de Alburquerque. A/HRC/12/24. IN HUMAN RIGHTS COUNCIL (Ed.). New York, UN.

UNITED NATIONS (2009b) Statement - Twelfth Session of the Human Rights Council, A/HRC/12/24. http://www.ohchr.org/EN/Issues/WaterAndSanitation/SRWater/Pages/AnnualReports.aspx, Accesed 2 January 2015.

UNITED NATIONS (2010a) Declaration on the right to water. A/RES/64/292. General Assembly, New York, UN. http://www.un.org/en/ga/64/resolutions.shtml Accessed 15 April 2015. 
UNITED NATIONS (2010b) Human rights and access to safe drinking water and sanitation. A/HRC/RES/15/9. New York, UN. http://daccess-ddsny.un.org/doc/UNDOC/GEN/G10/166/33/PDF/G1016633.pdf?OpenElement Accessed 15 April 2015.

UNITED NATIONS (2010c) Report of the independent expert on the issue of human rights obligations related to access to safe drinking water and sanitation, Catarina de Alburquerque. A/HRC/15/31. New York, UN.

UNITED NATIONS (2012) Report of the independent expert on the issue of human rights obligations related to access to safe drinking water and sanitation, Catarina de Alburquerque. A/67/270. New York, UN. http://daccess-ddsny.un.org/doc/UNDOC/GEN/N12/456/53/PDF/N1245653.pdf?OpenElement Accessed 11 February 2015.

UNITED NATIONS GENERAL ASSEMBLY (2014) Report of the Open Working Group of the General Assembly on Sustainable Development Goals, Resolution A/68/970. New York.

UNITED NATIONS GENERAL ASSEMBLY (2015) The human rights to safe drinking water and sanitation - Resolution A/RES/70/169. 2015.

WASHWATCH.ORG (2014) http://www.washwatch.org/en/.

WORLD HEALTH ORGANIZATION AND UNICEF (2010) Rapid Assessment of drinking-water quality in the Republic of Nicaragua. Country report of the pilot project implementation in 2004-2005. Geneva.

WSP (2012) Economic impact of poor sanitation in Africa: Mozambique. Washington DC, Water and Sanitation Program.

ZHOU, P., ANG B. W. \& ZHOU D.Q. (2010) Weighting and Aggregation in Composite Indicator Construction: a Multiplicative Optimization Approach. Social Indicators Research, 96, 169-181. doi: 10.1007/s11205-009-9472-3 